\title{
Coronary dominance and predictors of adverse events during coronary interventional procedures: an observational study
}

\author{
Navaraj Paudel*, G.S. Jha, V.M. Alurkar, Ramchandra Kafle, Subash Sapkota
}

Department of Cardiology, Manipal Teaching Hospital, Pokhara, Nepal.

\section{DOI Name}

http://dx.doi.org/10.3126/jaim.v6i1.18311

\section{Keywords}

coronary dominance, adverse events, coronary interventions

\section{Citation}

Navaraj Paudel, G.S. Jha, V.M. Alurkar, Ramchandra Kafle, Subash Sapkota. Coronary dominance and predictors of adverse events during coronary interventional procedures: an observational study Journal of Advances in Internal Medicine 2017;06(01):4-8.

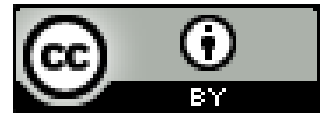

This work is licensed under a Creative Commons Attribution 3.0 Unported License.

\section{ABSTRACT}

Background: Coronary dominance is associated with adverse peri-procedural events during coronary interventions. There are limited data regarding events during coronary angiography in Nepal.

Aims and methods: The aim of this article is to get information regarding events during invasive procedures of this region which has a large feeder population. All the cases undergone cardiac interventional procedures were included and analyzed.

Results: Out of 200 cardiac interventional procedures, 160 cases underwent coronary angiography (CAG) and 20 percutaneous coronary intervention ( $\mathrm{PCI}$ ). $54 \%$ of the study populations were male. The mean age of study population was 61.2 years (range: $29-85$ years). Most common indication for performing CAG was for post ACS (69\%) followed by chronic stable angina (CSA) (16\%). Most common finding in CAG was SVD (35\%) LAD was the commonest (55\% of SVD), DVD (19\%), non-critical CAD (13\%), TVD (14\%) and left main (2\%). Myocardial bridging was seen in $2 \%$ and $15 \%$ had normal coronaries. Commonest risk factor for CAD was Hypertension (45\%) followed by smoking (35\%) and diabetes (16\%). CAG was most commonly performed from right radial (70\%) followed by right femoral (24\%), left radial (5\%) and left femoral (1\%). $78 \%$ of patients had right dominance, $16 \%$ had left dominance while $6 \%$ had co-dominance. Out of 40 non-right dominant (left or co-dominant) patient twenty three (57.5\%) were female. There was no significant association of left dominance with the gender although the odds ratio was high (1.8) in female gender ( $\mathrm{P}=0.12)$. Considering Left dominant patients only, the odds ratio of Tiger catheter versus Judkins Right (JR) is 8.33 but not statistically significant $(\mathrm{P}=0.17)$. Major complications encountered were ventricular tachycardia (VT) in 4 cases. The odds for VT with left dominance and right dominance was high with statistical significance [OR: 53.48, C.I :( 2.79-1023.4); $P=0.002]$.

Conclusion: Ventricular tachycardia which is among the major complication is found to be significantly associated with left dominance. Further studies are necessary to evaluate the evidence provided by this study.

\section{INTRODUCTION}

An artery providing the posterior descending artery (PDA) is considered as dominant in terms of coronary circulation. Most of the time after the crux, the PDA arises and supplies the posterior inter-ventricular septum and also gives major posterior-lateral (PL) branches to right ventricle. ${ }^{1} \mathrm{~A}$ codominant condition is a condition when there is mixed supply in posterior region of heart. $85 \%$ of times it is right dominant which means PDA is formed by right coronary artery (RCA), $7.5 \%$ left dominant where PDA is formed by Left circumflex artery (LCX) and remaining $7.5 \%$ co-dominant (originating from both RCA and LCX). Most of the time a PL is supplied by LCX

\footnotetext{
* Corresponding author Navaraj Paudel,

MCOMS-MTH, Phulbari-11, Pokhara, Kaski, Nepal.

Email:drnavarajdm@gmail.com
} 
and PDA by RCA. ${ }^{2}$ There are studies showing peri-procedural myocardial infarction and adverse outcomes in those patients who have left dominance..$^{2-4}$ The studies mainly assessed procedural outcomes in patients undergoing percutaneous coronary interventions ( $\mathrm{PCl}$ ). There is limited knowledge about the relation between coronary dominance patterns and the risk of various adverse clinical events that can occur following coronary angiography in Nepal. This study aims to find the adverse events following coronary interventions in this region.

\section{METHODS:}

The study population included all the cases undergone coronary interventions in Manipal Teaching Hospital, Pokhara after ethical clearance. It was a cross-sectional descriptive observational study. Coronary dominance was classified into right, left or co-dominant by two experienced analysts who inspected the coronary angiography of all the enrolled patients. A coronary artery system was classified as right dominant when the PDA originated from the right coronary artery (RCA), while left dominance was defined when the PDA originated from the left circumflex artery (LCX). A co-dominant coronary system was categorized when the PDA rose from the RCA in combination with a large PL branch originating from the LCX reaching near the posterior inter-ventricular groove. ${ }^{1-2}$ Coronary angiography was performed by Artis Zee floor ${ }^{R}$ model of SIEMENS Company. Diagnostic catheters used were Tiger and Judkins (right and Left). Data were collected in a preformed proforma and analyzed in SPSS software version 16. The significant difference between two groups was compared using ANOVA. Pearson's correlation coefficient, Chi-square test, t-tests etc was used to find group association. Odds ratio was calculated for required appropriate values and $p$ values were considered significant at a predetermined $\infty$ level of $5 \%$.

\section{RESULTS:}

Out of 200 interventional procedures in the cardiac catheterization laboratory, 160 cases underwent CAG and 20 $\mathrm{PCl}$. $54 \%$ of the study populations were male. The mean age of study population was 61.2 years (range: $29-85$ years). Most common indication for performing CAG was for post ACS (69\%) followed by chronic stable angina (CSA) (16\%). Most common finding in CAG was SVD (35\%) -LAD was the commonest (55\% of SVD), DVD (19\%), non-critical CAD (13\%), TVD (14\%) and left main (2\%). Myocardial bridging was seen in $2 \%$ and $15 \%$ had normal coronaries (Table 1).
Table 1.

\begin{tabular}{clcc}
\hline SN & \multicolumn{1}{c}{ CAG findings } & Number & $\%$ \\
\hline 1 & Single vessel disease (LAD) & $63(35)$ & $35(55.55)$ \\
2 & Double vessel disease (DVD) & 34 & 19 \\
3 & Non-critical CAD & 23 & 13 \\
4 & Triple vessel disease (TVD) & 26 & 14 \\
5 & Left main disease (LM) & 4 & 2 \\
6 & Myocardial bridging & 3 & 2 \\
7 & Normal coronaries & 27 & 15 \\
\hline
\end{tabular}

Commonest risk factor for CAD was Hypertension (45\%) followed by smoking (35\%) and diabetes (16\%). CAG was most commonly performed from right radial (70\%) followed by right femoral (24\%), left radial (5\%) and left femoral (1\%). $78 \%$ of patients had right dominance, $16 \%$ had left dominance while $6 \%$ had co-dominance. Out of 40 non-right dominant (left or co-dominant) patient twenty three (57.5\%) were female (Table 2).

Table 2:

\begin{tabular}{|c|c|c|c|}
\hline SN & $\begin{array}{c}\text { Coronary } \\
\text { Dominance }\end{array}$ & $\begin{array}{l}\text { Gender } \\
\text { (Number) }\end{array}$ & $\begin{array}{c}\% \text { (of specific } \\
\text { dominance) }\end{array}$ \\
\hline \multirow{2}{*}{1} & \multirow{2}{*}{ Right } & Male (75) & 53.57 \\
\hline & & Female (65) & 46.33 \\
\hline \multirow{2}{*}{2} & \multirow{2}{*}{ Left } & Male (11) & 37.93 \\
\hline & & Female(18) & 62.07 \\
\hline \multirow{2}{*}{3} & \multirow{2}{*}{ Co-dominant } & Male (6) & 45.45 \\
\hline & & Female(5) & 54.55 \\
\hline
\end{tabular}

There was no significant association of left dominance with the gender although the odds ratio was high in female gender as shown in Table 3.

Table 3.

\begin{tabular}{lcccc}
\hline Parameters & Male Female & $\begin{array}{c}\text { Odds } \\
\text { ratio }\end{array}$ & p-value \\
\hline $\begin{array}{l}\text { Patients with left } \\
\text { dominance }\end{array}$ & 11 & 18 & & 0.12 \\
$\begin{array}{l}\text { Patients without left } \\
\text { dominance }\end{array}$ & 81 & 70 & & \\
\hline
\end{tabular}

Major complications encountered were ventricular tachycardia (VT) in 4 cases, immediately terminated using DC cardioversion. VT was encountered in all patients who had left dominance. The odds for VT with left dominance and right dominance is shown in Table 4. 
Table 4:

\begin{tabular}{lllll}
\hline Parameters & VT (Yes) & VT (No) & $\begin{array}{l}\text { O d d s } \\
\text { ratio }\end{array}$ & p-value (C.I.) \\
\hline LD (Yes) & 4 & 25 & 53.48 & $\begin{array}{l}0.0002 \\
\text { LD (No) }\end{array}$ \\
\hline
\end{tabular}

Non-dominant RCA hooked with Tiger catheter was considered to precipitate in all of them (Table 5) as it hooked deep and directed into conus branch. No death was encountered.

Table 5.

\begin{tabular}{llll}
\hline SN & Catheter used & Dominance & $\begin{array}{c}\text { Ventricular } \\
\text { Arrhythmias }\end{array}$ \\
\hline & Right & None \\
1 & Tiger & Left & 4 \\
& Co-dominant & None \\
& $\begin{array}{l}\text { Judkins left } \\
\text { and right }\end{array}$ & Any & None \\
\hline
\end{tabular}

Considering Left dominant patients only, the odds ratio of Tiger catheter versus Judkins Right (JR) is 8.33 but not statistically significant as shown in the table 6 :

Table 6:

\begin{tabular}{lcccc}
\hline $\begin{array}{c}\text { Tiger } \\
\text { Catheter }\end{array}$ & VT (Yes) & VT (No) & $\begin{array}{c}\text { Odds } \\
\text { ratio }\end{array}$ & p-value (C.I.) \\
\hline Yes & 4 & 13 & & 0.17 \\
No & 0 & 12 & & $(0.40-170.99)$ \\
\hline
\end{tabular}

Other arrhythmias included: Supraventricular tachycardia in one and atrial fibrillation in two cases which were pharmacologically cardioverted. Neither patient had dissection or myocardial infarction. Other minor complications observed were local hematomas following femoral procedures and rigors in $5 \%$ of cases and 1 patient had vaso-vagal shock during femoral puncture.

Total $20 \mathrm{PCl}$ are performed so far mostly in mid and proximal LAD (10 cases). $19 \mathrm{PCl}$ cases were right dominant while 1 patient was left dominant. A person with left dominant $\mathrm{PCI}$ (done in mid LAD for 95\% Type B lesion) had $\mathrm{F}$ type of coronary dissection and needed CTVS assistance.

\section{DISCUSSION:}

Coronary procedures are routinely performed in various parts of the world. The procedures are routinely performed in MTH which caters the only cathlab available in large feeding population of whole western part of Nepal. Coronary angiography was performed for all indicated patients. ${ }^{5}$

The most common indication for the CAG was for the patients with ACS (69\%) followed by CSA (15\%). As per the indication made by ACC/AHA, patients with ACS mostly STEMI has Class la recommendation and patients with higher grades (2 or more) of angina according to Canadian cardiovascular Society (CCS) are considered to be candidates for CAG. ${ }^{5}$ Most common finding in CAG was single vessel disease with Left anterior descending (LAD) artery involvement. This was similar to findings in other studies. ${ }^{6-8}$

In this study, out of 180 coronary procedures (including CAG and $\mathrm{PCl}$ ), One hundred and forty (78\%) patients had right dominance, Twenty-nine (16\%) had left dominance and eleven (6\%) of patients had co-dominance. Out of 40 left or co-dominant patient thirty (57\%) were female (Table 2 ). There was no significant association of dominance and the gender in our study. This study although small shows more percentage of patients had right-dominance than literature. ${ }^{1-2}$

As with any invasive procedure, there are specific patientdependent and procedure-related complications that are inherent to the test. Complications range widely from minor problems with short term squeale to life threatening situations that may cause irreversible damage, if urgent care is not provided. Fortunately, the associated risks have decreased significantly since the inception of CAG due to advanced equipment design, improved peri-procedural management, and increased experience of diagnostic centers and operators. Major complications from cardiac catheterization occur in less than $2 \%$ of the population, with mortality of less than $0.08 \% .^{9-}$ ${ }^{10}$ In our study $10(5 \%)$ patients has minor allergic reactions in the form of wheal and rashes. No respiratory symptom or anaphylaxis occurred. This observation was similar to other studies where due to use of recent low osmolar contrast materials, the allergic reaction is very less. ${ }^{9}$ Also few local hematomas were the only vascular complications observed in patients undergone procedures using femoral route. It was not seen in patients performed procedures using radial route. ${ }^{11}$

In this study, four patients (2.22\%) had ventricular tachycardia (VT) as major complication. All of them were cardioverted using DC shock. Angiographically, they all were left dominant. The odds for VT with left dominance and right dominance was high with statistical significance $(P=0.002)$. This result was similar to other studies showing peri-procedural myocardial infarction and adverse outcomes in those patients who have left dominance. ${ }^{2-4}$ Now a days, with the advanced techniques and experienced interventionists, major complication has 
decreased drastically to less than $1 \%$. Complications like anaphylaxis are less than $0.01 \%$, Stroke and myocardial infarction less than $0.1 \%$. Mortality due to CAG is also less than $0.1 \% .5,9,10,12$ Non-sustained self limiting atrial and ventricular arrhythmias are frequently encountered but one should pay good attention to avoid major life threatening sustained arrhythmias. ${ }^{13}$

Ventricular arrhythmias are common with higher sized catheters as more with $5 \mathrm{~F}$ than $4 \mathrm{~F}$ as shown in a study by Chen $\mathrm{J}$ et al. ${ }^{14}$ Novel guiding catheters made especially for trans-radial procedures to hook both right and left coronary ostia are available which are found to be safer. ${ }^{15}$ Our study compared use of Tiger versus Judkins catheter to hook non-dominant RCA. Non-dominant RCA hooked with Tiger catheter was considered to precipitate VT in all of them as it hooked deep and directed towards conus branch which supplies right ventricular outflow tract (RVOT). Considering
Left dominant/ non-right dominant patients only, the odds ratio of Tiger catheter versus Judkins Right (JR) was 8.33 but was not statistically significant $(p=0.17)$. As explained by Peter Amman in his study, procedural complications are greatly related to operators experience and catheter size and not merely the type of catheter used. ${ }^{12}$ Small sample size is the limitation of this study.

\section{CONCLUSION:}

Coronary dominance and adverse events/outcomes during cardiac interventional procedures is evident. Left dominance is associated with increased peri-procedural adverse events as VT was found high in left dominant patients in our study. Further studies are necessary to add upon the evidence provided by this study.

disease:Preliminary Findings on incidence of myocardial infarction and angina.J Chronic Dis1965;18:527-558.

7. Kern M. Catheterization and angiography. In: Goldman L,Schafer Al, eds. Cecil Medicine . 24th ed. Philadelphia, PA: Saunders Elsevier; 2011:chap 57.

8. Popma JJ. Coronary arteriography. In: Bonow RO, Mann DL,Zipes DP, Libby P, eds. Braunwald's Heart Disease: A Textbook of CardiovascularMedicine. 9th ed. Philadelphia, Pa: Saunders Elsevier; 2011:chap 21.

9. Morteza Tavakol, Salman Ashraf \& Sorin J. Brener. Risks and Complications of Coronary Angiography: A Comprehensive Review. Global Journal of Health Science: Vol. 4, No. 1; January 2012.

10. Adams, D. F., Fraser, D. B., \& Abrams, H. L. (1973). The complications of coronary arteriography. Circulation, 48 (3), 609-618.

11. Babu, S. C., Piccorelli, G. O., Shah, P. M., et al. (1989). Incidence and results of arterial complications among 16,350 patients undergoing cardiac catheterization. J Vasc Surg, 10 (2), 113-116.

12. Peter Ammann, Hans P. Brunner-La Rocca, Walter Angehrn, Hans Roelli, Markus Sagmeister, and Hans Rickli. Procedural Complications Following Diagnostic Coronary Angiography Are Related to the Operator's Experience and the Catheter Size. Catheterization and Cardiovascular Interventions 59:13-18 (2003).

13. Nishimura RA, Holmes DR, McFarland TM, Smith HC, Bove 
AA. Ventricular arrhythmias during coronary angiography in patients with angina pectoris or chest pain syndromes. Am J Cardiol. 1984;53:1496-9.

14. Chen J, Gao L, Yao M, Chen J. Ventricular arrhythmia onset during diagnostic coronary angiography with a 5F or 4F universal catheter. Rev Esp Cardiol. 2008 Oct;
61(10):1092-5.

15. Kim SM, Kim DK, Kim DI, Kim DS, Joo SJ, Lee JW. Novel diagnostic catheter specifically designed for both coronary arteries via the right transradial approach. A prospective, randomized trial of Tiger II vs Judkins catheters. Int J Cardiovasc Imaging. 2006;22: 295-303. 